were generally better. The dose was increased to fivetwelfths of a grain. -16 th : These hopes were arrested, as though the bowels were open twice a day and the tongue clean, there were some fresh spots, slight papules, with some flatulence. Dose increased to half a grain.-19th: Dose three-quarters of a grain; tongue clean, bowels open, rash somewhat paler; pulse 84 , weak ; flatulent colic. - 23rd: Dose one grain. - 26th : No fresh spots, rash paler; hepatic pain under right shoulder.-30th : The legs have no more spots, but there is increased formation of scale; there are also fresh patches formed on the elbows, arms, and hands ; pulse 72, fair ; tongue clean; bowels open twice a day; these are now so sensitive that directly she takes her tea in the morning she has to hurry to relieve them. Notwithstanding that it appeared as if the chrysophanic acid had reached the utmost stage of toleration, I was desirous of seeing if a larger dose would have some effect on the eruption, and consequently having told her to discontinue the powders if the symptoms required it, the dose was increased to one grain and a half three times a day.-.July 3rd: The powders ex. eited great vomiting, and the scaly formation very much increased; pulse 72, full and soft; discontinued powders on July 1st. she was then ordered a carminative mixture, and afterwards arsenic, and is now nearly well. Notwithstanding that these cases showed no special cutaneous action of chrysophanic acid, yet thinking that there was some evidence of increased biliary secretion apart from simple purgative action on July 29 th, I tried it in the next case.

CASE 3.-C. M—, a widow, aged fifty-seven, a large flabby fat woman with two large bright-red patches of psoriasis, exfoliating large scales, covering one elbow and one knee, each patch being three inches square. Tongue foul and coated; pulse 72 , weak ; bowels confined. She began with half a grain doses of acid on July 28th, increased to three-quarters on July 31st. - August 1st: There is no improvement in either the rash or the tongue; the bowels are purged twice a dav, and the powders have each time produced vomiting; the conjunctivæ are still mahogany colour.

Observations. - The results obtained in these cases were not such as to encourage further trials, nor to confirm the supposition that there was any specific cutaneous action; on the contrary, it leads to the deduction that in the successful case published in THE LANCET the good result must have been due to continuous purging, and if this deduction is correct, then there are other medicines whose action is equally efficacious, and at the same time free from those irritating properties which characterise chrysophanic acid. In three other cases in which this was tried it acted so immediately as an emetic that it would be absurd to consider them in connexion with a constitutional action. In the second case where the drug was tolerated better than in the others at the time when, if any, a specific benefit ought to have been manifested, the disease increased in virulence. It is possible that in future therapeutical works the acid will be quoted as a remedy for psoriasis, and in consequence it may be tried by many gentlemen whom the persistence of the disease has sorely puzzled; it is with a view of pointing out what results may possibly be expected that the foregoing cases have been recorded and sent for publication.

Note.-The name chrysophanic acid is retained in the above observations, but I am informed that the proper name is chrysarobin. This is the active principle or one of the active principles of rhubarb; and I notice in the Pharmaceutical Journal the active principle of senna, supposed to be cathartine, has been resolved into three substances, one of which is chrysarobin. The action of the so-called chrysophanic acid resembles very much that produced by senna and all its preparations on some individuals.

The Surgical AID Society.-The Lord Mayor presided at the annual meeting of the subscribers to this Society, held at the City Terminus Hotel on Monday. The report stated that 1442 men, 2024 women, and 703 children had benefited by the charity during the past year. The amount expended in surgical appliances and surgeons' fees had been $£ 4005$. But for the receipt of a legacy of $£ 1307$, there would have been a considerable balance on the wrong side. His lordship regarded this state of things as unsatisfactory, as he thought legacies should go to the reserve fund.

\section{TREATMENT OF CHRONIC DYSENTERY BY LARGE INJECTIONS OF NITRATE OF SILVER SOLUTION.}

By GEORGE E. POST, M.D.,

PROFESSOR OF SURGERY IN THE SYRIAN PROTESTANT COLLEGE; SURGEON TO THE JOHANNITER HOSPITAL, BEYROUT.

THE patient is a European lady who has lived for about eight years in Syria, aged about thirty years, of healthy constitution, the mother of three healthy children. Partly as the result of nervous prostration, and partly from lacta. tion, she was attacked in the latter part of last autumn with pains in the back of the head and some confusion of the mental faculties. These symptoms, with persistent sleeplessness, continued until the beginning of the spring of the present year, when she was attacked with diarrhœa, which gradually assumed a dysenteric character. At the time when I first saw her, July 28th, her state was as follows:Great general debility and nervous prostration, nausea which was in part due to a mixture of catechu and other astringents which had been administered with a view of checking the diarrhœea; characteristic dysenteric evacna. tions, accompanied with severe colicky pains and abdominal rumbling and uneasiness. She was not at that time taking any precautions in diet, nor confining herself to bed. There was no elevation of temperature, but the expression of coun. tenance was haggard and worn. She was also much dis couraged about her state, and harassed by sleeplessness, and in despair of recovery. The tongue was somewhat roughened by the astringents which she had taken.

I commenced the treatment by fifteen-drop doses of castor. oil, a strict milk diet, rest in bed, and ten-drop injections of laudasum in starch to quiet the tenesmus. This treatment was continued for forty-eight hours, with the effect of bringing away a few scybala, and relieving to a certain extent the tenesmus and nausea and slightly improving the character of the discharges. On the afternoon of August lst an injection of three pints of water containing forty-five grains of nitrate of silver was prepared. The syringe was not, however, in good order, and not more than a pint entered the bowel. This was retained four or five minutes. It brought away with it mucus, greenish fæcal matter, a few scybala, and a little blood. A good deal of pain followed, and lasted for about an hour before it quite passed away. Shortly after the first motion she had another free from scybala. An hour and a half later another more copious, with considerable pain ; half an hour later a small one with little but mucus ; a little later some bloody mucus. As pain continued a laudanum and starch injection was administered. Twenty minutes later she had a small brownish stool, with a little mucus. After this she slept for threequarters of an hour, and woke to have a small mucus passage, after which she vomited. An hour later a small motion. Still an hour later a brownish stool with some greenish admixture and little mucus. Five other motions occurred during the next seven hours, the last looking like ordinary liquid fæecs. In the morning she was sick and vomited, but soon after, despite a few small motions, felt stronger. She took her milk and limewater better, and occasionally a teaspoonful of brandy. The headache had nearly passed away, and she slept fairly between the motions. To fever or quickening of the pulse. Abdominal pain much lessened. 'The history of the second day is briefly as follows:Motions: 9 A.M. ; 10, small but natural ; 12.30 P.M., small but natural, with a little greenish slime; 1 to 3 , four small motions, the last with specks of mucus; 3.30 to 6 , two motions, the last small but natural ; 7.30, small quantity of mucus. As there was some tenesmus without any passage an injection of starch and laudanum was administered, and half an hour later she fell asleep, and slept five hours, and awoke hungry. During the day the sickness of the stomach was much lessened, and she took and retained sufficient nourishment. In general she felt much better all through the day and night. During the remainder of the night of the second day she slept with little interruption. On the morning of the third day, at 6.30 , she had a natural motion, but with it a little mucus and blood, and slight abdominal pain before passing. At 7 A.M. a copious natural motion ; 1.45 P.M., small but natural, with a little mucus; 2.15 to 6 , two motions like the former of this day; 6.15 , a few 
scybala ; 8.15 , an injection of laudanum and starch (ten drops) was administered, after which she slept till 2 A.Mr., and again from 3 to 6 A.M., when she had a motion, not fluid and natural in colour, with the addition of a small patch of bloody mucus. The fourth day, at 7.15 A.M., a small natural motion; 9, a little mucus; 3 P.Mr., a small natural motion, after which two pints of the above-mentioned solution of nitrate of silver were injected. She would not allow the whole three pints to be thrown in on account of the pain which they caused. The injection was retained less than a minute. It brought away with it less than the first, but some scybala, less than before. She continued to have evacuations for three-quarters of an hour, the last being mucus without blood. The pain did not wholly cease for an hour and three-quarters, and then only after a laudanum injection. She continued weak and nauseated until 7 P.M. when she began to feel quite easy, and continued so until 9.15 P.M., when she fell asleep. After an hour of restless sleep she fell into a natural slumber, in which she continued uninterruptedly until morning. No motions since 4.15 P.M. The fifth day was a good one. She was able to knit a good part of the day. She had one motion between noon and 1 P.M., with a little mucus, and another at 2 P.M. quite natural, semi-solid. She slept soundly during the night. She seemed to have caught a little cold towards morning, from insufficient covering, and complained of soreness in the bones, \&c. It passed off, however, early in the morning of the sixth day. At 2 P.M. of the sixth day she had a small motion, quite solid. Began to long for food and experienced a hungry feeling, which the milk only took away for a short time. She took large quantities of the milk, but was not satisfied. She had neither pain nor ache, and the tongue was much cleaner. On the eighth day she began to take a little breast of chicken and soft-boiled eggs, and day by day her diet was improved. On the fifteenth day she had had no return of diarrhoea, had been up for three afternoons, walking a little about the room, and feeling stronger each day. Ten days having since elapsed without any further tidings, it may be inferred that she is now quite well.

As the treatment had to be conducted, after the first visit, by correspondence, at a distance of fifteen hours by messenger, some delay unavoidably occurred in advising the successive steps of the management of the case. Had the patient been within reach, I should have given the first injection a day sooner, and the second two days sooner. The return to a more nourishing diet might silso have been slightly accelerated. On the whole, however, the case leaves little to regret, and nothing to desine. The very small quantity of laudanum required after the inainguration of the nitrate of silver treatment is most instructive. The easy and continuous sleep after such prolonged insomnia is also a feature worth noting. Any treatment which can cure so aggravated a form of dysentery as this one in so short a time, and with no drawback but the temporary pain of the injection, is an invaluable resource to the practitioner.

Beyrout.

\section{ON A CASE OF \\ SIMPLE FRACTURE OF THE STERNAL END OF THE CLAVICLE INTERNAL TO THE RHOMBOID LIGAMENT.}

BY G. OWEN WILLIS, L.R.C.P., L.R.C.S. ED., SENIOR SURGEON TO THE MONMOUTH HOSPITAL.

J. E-, aged fifty-four, a labouring man, was admitted into the Monmouth Hospital on July 18th, 1881. He stated that two hours previously he slipped off a hayrick, fell heavily on his outstretched right hand, and also struck his right shoulder. On examination a simple fracture of the sternal end of the right clavicle was discovered within a quarter of an inch of the sternal head of the bone. The direction of the fracture was obliquely downwards and outwards. The outer fragment rode high in the neck from the action of the clavicular fibres of the sterno-clavicular mastoid muscle and the weight of the arm. The fractured end of the outer portion was very sharp, and threatened to lacerate the skin. The inner fragment presented no marked sign of dis- placement, was freely movable, easily depressed, and on pressure the sensation was conveyed to the finger of its being loose and rolling. He had fractured the sixth and seventh ribs in front of and close to their angles. My efforts to adapt the broken ends of the clavicle were but partially successful. Apposition of the ends was gained when the right arm was raised and the fingers of the right hand

Fig. 1.



touched the left ear, the point of the elbow being slightly tilted forwards by a pillow. Any attempt to fix the limb in this position was not tolerated for long. I had to content myself with slinging the arm and placing $\mathbf{a}$ pad of cotton-wool on the shaft of the clavicle; this last kept in position by strips of plaster crossing the chest from back to front. He had a sharp attack of pleurisy, and was



very restless, often getting in and out of bed, but recovered and was discharged convalescent on August $29 \mathrm{th}, 1881$. I saw him again on August 30th, 1882, when a photograph and cast were taken. The broken end of the outer fragment was rounded off and lessened by absorption, and he had fibrous union permitting of some movement. That morning he had done a bit of stiff digging, and considered his recovery a good one.

I have been influenced to publish this case at such length because fracture of the sternal end of the clavicle is rare, whilst fracture internal to the rhomboid ligament is very rare. Holmes, in his " Principles and Practice of Surgery," 1875, says, "it has not as yet been proved." Bryant makes no mention of the injury, and $I$ am indebted to the kindness and courtesy of my old teacher, Mr. Henry Morris, of the Middlesex, for the following references:-Hamilton refers to three cases (in a record of 105 fractures of the clavicle) in which the fracture was within one inch of the sternum, and he says that in such fractures, which are of course, within the fibres of the rhomboid ligament, there is but little displacement. Lonsdale mentions a 